\title{
Changes in maximum water holding capacity of chernozem soil caused by soil compaction
}

\author{
Yuriy Bekhovykh*, Larisa Bekhovykh, Aleksey Lyoevin, and Evgeniy Sizov \\ Altai State Agricultural University, pr. Krasnoarmeyskiy, 98, 656049 Barnaul, Russia
}

\begin{abstract}
The goal of the studies presented in the work is to estimate the changes in the maximum water holding capacity of the soil caused by soil compaction. The object of the research is a loam type of chernozem soil. The research shows that the maximum water holding capacity is a function of the soil density change and indirectly depends on the action of soil compaction factors, including external pressure level, the number of impacts on soil cover, as well as on soil moisture. Soil moisture is indicated as the most important factor in changing the maximum water holding capacity caused by soil compaction. The decrease in the maximum water holding capacity caused by soil compaction is more obvious with an increase in soil moisture, both in the research of the number of impacts and external pressure influence on this indicator. The results of the work show that the change in the maximum water holding capacity caused by a compacting action significantly depends on the initial value of the soil addition density.
\end{abstract}

\section{Introduction}

Overconsolidation of the soil cover is one of the factors negatively affecting its fertility and crop yields [1].

Optimal densities are within 1.1-1.3 g/ $\mathrm{cm}^{3}$ for most soil types in Russia [2-4]. On soils with optimal density plants consume moisture more productively, aeration of the root layer is carried out [4], and the yield of cultivated crops increases [4,5].

However, in the conditions of modern agricultural production, there is a tendency to increase the weight of agricultural machinery, which increases the compaction effect on the soil by its undercarriage systems and undercarriage systems of the trailer units used in soil treatment [6-9]. Soil compaction leads to a reduction in the pore space of the soil [10], a deterioration in the water-physical characteristics [11], resulting in a decrease in yield [12]. Soil decomposition processes are slow and often require special energy-intensive measures [13] which ultimately increase the cost of crop cultivation. In this regard, it is rational to carry out crop production taking into account changes in water, air and other soil properties during soil compaction, which will undoubtedly contribute to increasing soil fertility and yield.

The aim of this work is to investigate the potential water content of soil compaction.

\footnotetext{
*Corresponding author: Phys_asau@rambler.ru
} 


\section{Materials and methods}

The object of the study is the leached medium loam chernozem of the Priobskoye Plateau.

The objectives are as follows:

1) to identify an indirect relationship between the maximum water holding capacity of the soil and its bilk density;

2) to identify a tendency of change in the maximum water holding capacity of the soil of different moisture conditions in relation to the number of fixed pressures;

3 ) to identify a correlation between the change in the maximum water holding capacity of the soil of different moisture conditions and the influence of different pressures.

The experimental plots were laid on the fallow field of the "Prigorodnoye" training and experimental farm, located in the forest-steppe zone of the West Siberian Plain, in the north-east of the Priobskoye Plateau. The different pressures on the soil were regulated by the action of a fixed weight load on the compactors of different support areas. An unconsolidated area of black fallow served as a control area. Different soil moisture in the experimental plots was created by artificial moistening.

The determination of the maximum water holding capacity was carried out by a calculation method based on the results of direct measurements of moisture, bulk density and particle density of the soil [14].

\section{Results and discussion}

The studied chernozem relates to a loam type of leached chernozem soils with a predominance of medium loam in the soil horizons. The chernozem profile is classical with humus horizon $\mathrm{A}$, transitional $\mathrm{AB}$, illuvial horizon $\mathrm{B}$, transitional $\mathrm{BC}$, and carbonate horizon of the parent rock $\mathrm{Ck}$. The surface layer from which the samples were taken was the upper half of the humus arable horizon A $(0-29 \mathrm{~cm})$. According to morphological structure, it is moist, black-and-brown with the pronounced lumpy-powder-like structure of aggregates, loose, loam.

According to the granulometric composition, the upper layer of the arable horizon of the studied chernozem relates to the medium loams (Table 1).

Table 1. Granulometry of the arable layer of the studied chernozem on the experimental plot

\begin{tabular}{|c|c|c|c|c|c|c|c|c|c|}
\hline \multirow[b]{2}{*}{$\begin{array}{c}\text { Soil } \\
\text { horizon }\end{array}$} & \multirow[b]{2}{*}{$\begin{array}{c}\text { Depth, } \\
\mathrm{cm}\end{array}$} & \multicolumn{7}{|c|}{ Fraction content (in \% content of absolutely dry soil) } & \multirow[b]{2}{*}{$\begin{array}{l}\text { Name of the } \\
\text { granulometric } \\
\text { composition } \\
\text { of the soil }\end{array}$} \\
\hline & & $\begin{array}{c}1- \\
0.25 \\
\mathrm{~mm}\end{array}$ & $\begin{array}{c}0.25- \\
0.05 \\
\mathrm{~mm}\end{array}$ & $\begin{array}{c}0.05- \\
0.01 \\
\mathrm{~mm}\end{array}$ & $\begin{array}{c}0.01- \\
0.005 \\
\mathrm{~mm}\end{array}$ & $\begin{array}{c}0.005- \\
0.001 \\
\mathrm{~mm}\end{array}$ & $\begin{array}{c}<0.001 \\
\mathrm{~mm}\end{array}$ & $\begin{array}{c}\sum_{\text {fractions }} \\
<0,01 \\
\text { mm }\end{array}$ & \\
\hline A(hum) & $0-29$ & 7.36 & 34.68 & 24.44 & 6.40 & 5.24 & 21.88 & 33.52 & medium loam \\
\hline
\end{tabular}

As can be seen from Table 1, in the granulometric composition of the studied leached chernozem prevail fractions of medium sand $(0.25-0.05 \mathrm{~mm})$, coarse dust $(0.05-0.01 \mathrm{~mm})$ and a clay fraction (less than $0.001 \mathrm{~mm}$ ). The maximum humus content in the surface layer of the chernozem arable horizon did not exceed $3.4 \%$. According to the $\mathrm{pH}=6.7$, the soil is neutral or close to such.

In order to create a weight load in the study of changes in the maximum water holding capacity of the soil of different moisture from the number of fixed pressure impacts, it was decided to use a load that produced a pressure of $100 \mathrm{kPa}$ by a soil compactor of a certain area. Modern agricultural machinery with close average soil pressure parameters of a single unpaired wheel is most often used in modern agricultural production.

The results of the studies show that maximum water holding capacity is a function of changes in soil density (Fig. 1). The approximation curve of dependence is well described 
by a logarithmic function and an exponent. The numerical coefficients included in the function of changes in maximum water holding capacity from density reflect the characteristics of the granulometric composition of the studied soil and, supposedly, the content of organic matter in the soil and require further study.

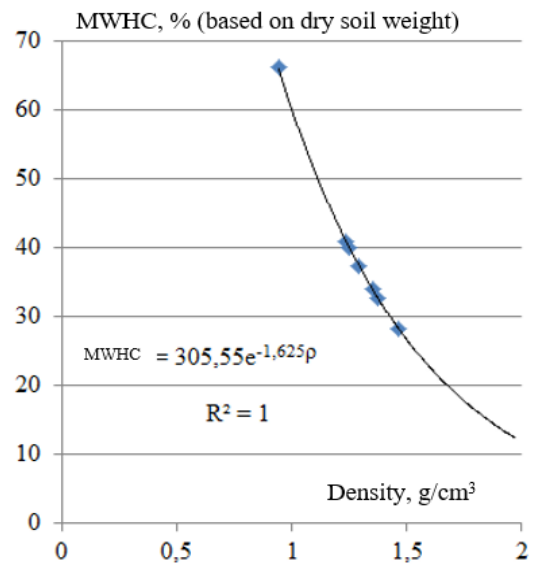

Fig. 1. Dependence of the maximum water holding capacity of the surface layer of the studied chernozem on the bulk density of the soil

The study of changes in the maximum water holding capacity of the soil of different moisture content on the number of impacts of the soil compactor creating a fixed pressure (Table 2) revealed that an increase in soil moisture is a determining factor in reducing the maximum water holding capacity under repeated loads on the soil layer. For example, when the surface layer of the studied chernozem was moistened to values close to $30 \%$ of the dry soil mass, even a single compaction with an external pressure of $100 \mathrm{kPa}$ led to an increase in the soil compaction density and a change in the pore space characteristics, which reduced maximum water holding capacity by almost half.

With a decrease in soil moisture, the change in maximum water holding capacity due to external pressure occurs similarly, but the potential moisture content decreases less intensively. According to the graphs (Figure 2), the dependence of the maximum water holding capacity on the number of compactor impacts on the soil shows that the maximum water holding capacity decreases significantly at the first impacts, with the density increasing most intensively [15]. The coefficient of potential moisture content decreases and approaches the abscissa axis asymptotically under multiple impacts of external pressure (Fig. 2). This peculiarity is evident due to the fact that the soil density under the impact of external pressure tends to "saturation" [15].

Table 2. Dependency of density $\left(\mathrm{g} / \mathrm{cm}^{3}\right)$ and maximum water holding capacity (\% of dry soil mass) of the studied chernozem on the number of impacts $(\mathrm{N})$ of the compactor creating a pressure of $100 \cdot 10^{3} \mathrm{~Pa}$ on the soil

\begin{tabular}{|c|c|c|c|c|}
\hline \multirow{2}{*}{$\mathrm{N}$} & \multicolumn{4}{|c|}{ The bulk density of the soil at the different moisture content $\left(\mathrm{g} / \mathrm{cm}^{3}\right) /$} \\
\cline { 2 - 5 } & $14 \%$ & $18 \%$ & $24 \%$ & $28 \%$ \\
\hline 0 & $0.942 / 66.2$ & $0.942 / 66.2$ & $0.942 / 66.2$ & $0.942 / 66.2$ \\
\hline 1 & $1.236 / 40.9$ & $1.257 / 39.5$ & $1.299 / 37.0$ & $1.350 / 34.1$ \\
\hline 5 & $1.250 / 40.0$ & $1.299 / 37.0$ & $1.347 / 34.2$ & $1.375 / 32.7$ \\
\hline 10 & $1.291 / 37.4$ & $1.309 / 36.4$ & $1.391 / 31.9$ & $1.467 / 28.2$ \\
\hline
\end{tabular}




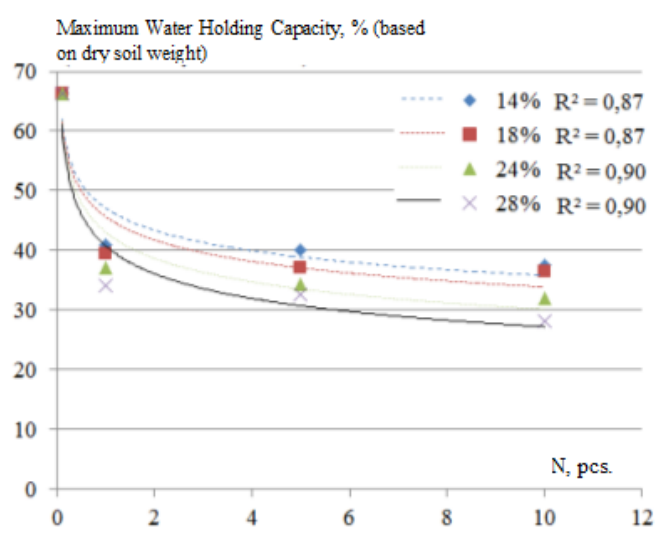

Fig. 2. Dependency of the maximum water holding capacity of chernozem on the number of impacts $(\mathrm{N})$ of external fixed pressure $\left(100 \cdot 10^{3} \mathrm{~Pa}\right)$

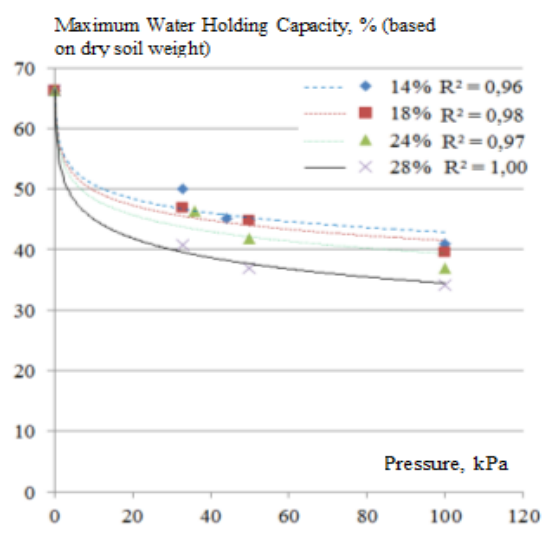

Fig. 3. Dependency of the maximum water holding capacity of chernozem on the value of external pressure

Figure 3 illustrates the graphically represented approximation of the dependence of the maximum water holding capacity of the studied chernozem on different external pressure created by soil compactors with different areas of the compaction surface. The graphically reflected dependence of the maximum water holding capacity on external pressure (Figure 3 ) is non-linear and tends to asymptotic decrease of the values. The graphs (Fig. 3) also reflect the fact that soil moisture is the most important determinant of the degree of potential moisture content.

The change in the maximum water holding capacity of the soil caused by the compaction impact strongly depends on the initial bulk density of the soil. The more the soil is loosened and the lower the initial density before compaction, the more it increases by a single compaction impact of a fixed pressure, while the pore space decreases more significantly and, as a result, the maximum water holding capacity, which depends on the number and volume of free pores that water can potentially occupy.

\section{Conclusions}

Based on the research results, the following conclusions can be drawn: 
1. the maximum water holding capacity is a function of changes in the soil density and indirectly influenced by soil compaction factors, including on the magnitude of external pressure, on the amount of its impacts on the soil cover, as well as on soil moisture;

2. soil moisture is the most significant factor determining the change in the maximum water holding capacity of the soil caused by compaction;

3. the decrease in the maximum water holding capacity of the soil caused by compaction is more visible with an increase in soil moisture, both when studying the influence of the number of impacts and the magnitude of external pressure on this indicator;

4. the change in the maximum water holding capacity caused by compaction effect significantly depends on the initial soil bulk density;

5. the indicator of the potential water holding capacity (maximum water holding capacity) of the soil asymptotically decreases with multiple impacts of external pressure and with an increase in its value.

\section{References}

1. A. G. Bondarev, Eurasian Soil Science, 5 (1990)

2. S. S. Sdobnikov, Agriculture, 2 (2000)

3. I. A. Chudanov, L.F. Ligastaeva, Agriculture, 4 (2000)

4. S. I. Dolgov, I. V. Kuznetsova, I. A. Modina, Problems of soil cultivation: reports of the International meeting dated June 13-15, 1968 (Varna, 1970)

5. Kh. Kh. Ashabokov, L. M. Khazhmetov, Yu. A. Shekihachev, materials of the International (correspondence) scientific-practical conference (2017)

6. N. N. Pogodin, V. V. Kuchko, F. A. Barsukevich, S. V. Shatilo, Melioraciâ, 59 (2008)

7. G. A. Okunev, N. A. Kuznetsov, AIC of Russia, 75(1) (2016)

8. Z. A. Godzhaev, A. M. Pogozhina, Tractors and agricultural machinery, 5 (2018)

9. G. A. Okunev, N. A. Kuznetsov, A. A. Brazhnikov, Bulletin of the Chelyabinsk State Agroengineering Academy, 69 (2014)

10. Yu. V. Bekhovykh, Bulletin of Altai State Agrarian University, 178 (2019)

11. V. Kh. Katz, S. V. Kuznetsov, Collection of scientific treatises VIM, 66 (1974)

12. V. P. Dyakov, All-Russian scientific and practical conference with international participation (2016)

13. A. G. Bondarev, I. V. Kuznetsova, P. M. Sapozhnikov, Eurasian Soil Science, 4 (1990)

14. A. F. Vadyunina, Z. A. Korchagina, Methods for the study of physical properties of soils (1986)

15. Yu. V. Bekhovykh, Bulletin of Altai State Agrarian University, 177 (2019) 